\title{
Explaining the Mediating Role of Knowledge Management between Organisation's Characteristics and Employee's Performance: A Public Sector Perspective
}

\author{
Adnan A. S. Al-Ali ${ }^{1} \&$ Jarrah F. Al-Mansour ${ }^{2}$ \\ ${ }^{1}$ College of Business Studies, Department of Management, Public Authority for Applied Education and Training, \\ (PAAET), Kuwait \\ ${ }^{2}$ AOU Business School, Faculty of Business Studies, Arab Open University, Kuwait \\ Correspondence: Jarrah F. Al-Mansour, AOU Business School, Faculty of Business Studies, Arab Open \\ University, Kuwait. E-mail: jarrah@aou.edu.kw
}

Received: August 11, 2020

doi:10.5539/ijbm.v15n12p132
Accepted: October 19, $2020 \quad$ Online Published: November 10, 2020

URL: https://doi.org/10.5539/ijbm.v15n12p132

\begin{abstract}
This paper aims to investigate the mediating role of knowledge management between organizational culture, structure, strategy, and employee and organisational performance. There is a significant research work on Knowledge Management (KM) globally; however, there is a dearth of research in contextualizing the concept in the Middle East. Therefore, adopting a multiple case-based approach, this paper conducted 478 surveys in five public organizations in Kuwait. The results suggested that KM could mediate the impact of organizational strategy and HRD structure. Surprisingly, organizational culture emerged as the only construct that remained uninfluenced by knowledge management practices. This research makes a vital contribution to the under-researched knowledge management concept in the region and the relevant cognitive understanding of social practice in relation to the HRD. It, therefore, proposes an integrative framework which specifies the conceptual linkages between organization characteristics and potential performance.
\end{abstract}

Keywords: knowledge management, human resources development, social practice, organization culture, employee performance, organizational performance

\section{Introduction}

Knowledge is seen as one of the biggest assets for any discipline for centuries, however, the term Knowledge Management (KM) is a contemprary phenomenon, which was coined in the 21 st century. As a young concept, it gained popularity in the lastest 10-15 years and has been researched as a driving force for business success. KM broadly means the practice of sharing, using, and managing knowledge and information in an organization. Over the years, the key organizational and managerial practices have undergone a sea change and attention to the core characteristics of any organization have become a prerequisite for its sustainability, success, and improvement. Amidst the transformation, KM emerged as one of the key characteristics.

Various scholars and researchers have been working on the concept and tried to explain it through different theories and concepts, such as KM is considered as a new discipline in its own right (Nelson and Winter, 1982; Penrose and Penrose, 2009). It is also a core mean that enables employees to use organizational resources (Darroch, 2005), and it is also understood as a process to share knowledge with social actors that allows organisations to compete (von Krough, 1998). KM is also about participation. As a general concept, it reflects a form of context, and defines who participates and how in the overall KM process (Nonaka et al., 2000).

Many argue that Knowledge Management is identical to the social practice. This is so because the process of Knowledge Management is about social practices of social actors within an organization, which forms a distinctive part of HRD practice. Knowledge-driven organizations focus on roles, communication practices, and scenario planning to encourage knowledge sharing. Therefore, Knowledge Management is a practice in itself, and does not necessarily entail a technological system (Davenport and Prusak, 1997). Such a practice is a key approach to improve organizational performance and encourage shared understanding among social actors. Organizations, with dynamic HRD practices, which integrate effective Knowledge Management processes in its daily practice, can promote shared knowledge amongst their employee worldwide (Yap and Bjorn-Andersen, 
1998; Gopeet al, 2018). Such employees will be in a better position to accomplish duties and ensure organizational performance.

In order to maximize the efficiency and boost the services offered to the citizens in Kuwait and to the public, Kuwaiti governments started using technology apps for communication and information to help with improving transparency and with increasing productivity. With easing and simplifying the procedure with the help of modernizing the laws, a proper working environment will be successfully implemented in the IT and E-government program.

Many researchers have identified issues and challenges of knowledge management practices in Kuwait (Hako, 2015) have pointed out several points of weaknesses and strengths in management system, which include ownership, transparency, technical capacity and regulatory capacity. The implied system is inadequately integrated with long-run plan in the State of Kuwait with little availability of technical staff.

Kuwaiti business organizations are, however, seems successful in implanting knowledge management practices, as Dzenopoljac al, (2018) noted that the usage of knowledge management methods in Kuwaiti organizations have affected innovation and business performances positively. Similarly, Al-Qarioti (2015) found that faculty members in Kuwait University evaluated that the knowledge management components are highly related to organizational performance. Al-ajmi B. al, (2015) had reviewed practices of knowledge management in Kuwaiti hospitals and found the three major knowledge management practices which are knowledge capturing, sharing, and generating. The implementation of the practices of knowledge management were rated very low in the tested hospitals, and didn't give much attention to the main activities that encourages the transfer.

The study of Chiabrishvili and Zaim (2018) revealed that there is a direct connection between knowledge management processes and the sustainability of Kuwaiti organizations. On the other hand, Elmorshidy (2018) found that perceived usefulness has a positive effect because of the knowledge management system quality, information quality, and service quality which resulted in having a positive effect on the actual use of knowledge management and had also increased the innovation for employees. Al-Ajami and Al-Qa'eed (2020) have revealed that the knowledge management have an impact and effect on the marketing performance in both small and medium projects in Kuwait.

Although the influence of the mediating role of knowledge management on organizational effectiveness has been thoroughly investigated (e,g., Zhenget al, 2010), still there is a dearth of research on understanding the simultaneous effects of knowledge management on HRD practices, which have direct impact on organizations overall performance particularly in Kuwaiti Public sector organisations. Public sector is selected as focal context for two reasons. Firslty, the literature seems providing sufficient evidence on the mediating role of knowledge management in organisation performance (e.g., Dzenopoljac al, 2018) ) However, public sector is an opportunity domain to bring a fresh data theory. Secondly, public sector is usually considered doubtful of it being performative as compared private business organizations as such organizations strive to improve because of their competitive environment (von Krough, 1998). It would, therefore, be interesting to explain how knowledge management plays its mediating role in determining the practices of these public sector organisations, so to provide more robust public policy inputs for overcoming the said performance gap.

This study explains the role of Knowledge Management as a mediating factor in providing a clearer understanding of the conceptual link between organizational characteristics and performance. The premise of the paper is that there is a lack of understanding of how organizational elements actually influence performance output deviated from relevant HRD practices. Since, we believe that individuals' interactions within organizations reflect their social practices, our purpose is to explain the mediating effect of knowledge management - as based on practice - on the relationship between organizational structures, strategy, culture, and HRD practices. To facilitate this purpose, the paper addresses five hypotheses aligned with their respective sections, elaborated from next section.

The theoretical foundation of this work can be rooted to the variables examined in this study. These attributes are organizational culture, organizational structure, organizational strategy, individual performance, and organizational performance. Also, these attributes are measured through the controlling role of knowledge management. The process of knowledge management and knowledge sharing reflects the routine interactions of the individuals which in turn represent their internal social practices with each other. Therefore, it can be stated that the process of knowledge creation represents the fragile asset of organizations that is embedded in individuals' social practice (von Krogh et al., 2012). 


\section{Social Practice and HRD Practices (Performances)}

The field of knowledge management has been recognized in a number of advanced conceptual models (e.g., Alavi and Leidner, 2001; Choi and Lee, 2002; Heisig, 2009). These models encompass effects of Knowledge Management on a wide range of business disciplines. For instance, the effect of Knowledge Management on HRD (Kiantoet al, 2017), organizational effectiveness (Zhenget al., 2010), firm performance (Palacios and José, 2006; Yang, 2010), types of innovation (Darroch \& McNaughton, 2002), social interaction and innovation performance (Huang \& Li, 2009), knowledge management processes (Allameh \& Zare, 2011), and team performance (Politis, 2003). Having said that, in spite of extensive research on Knowledge Management, there is a dearth of information in understanding how Knowledge Management affects HRD practices, which in turn affects performance of both employees and organizations in the public sector. It is argued that Knowledge Management is not a material object that can be predicted and controlled; rather, it is the accumulation of social interactions that leads to powerful knowledge sharing.

Knowledge Management focusses on the process of external and internal knowledge development in an organization (Davenport \& Prusak, 1998); therefore, it focuses on both performance and effectiveness. Knowledge sharing, on the other hand focusses on the transfer of knowledge from one individual to another or a group in an organization (Davenport \& Prusak, 1998). Furthermore, Gold et al. (2001) identified an additional element of Knowledge Management process called Knowledge Utilization and argued that it empowers the use of knowledge itself. Another study demonstrated that the effect of interpersonal trust on team performance is largely mediated by the intervening variables of knowledge acquisition (Politis, 2003).

Therefore, it was concluded that knowledge sharing, knowledge generation, and knowledge utilization contributes to organizations' HRD practices and reflects the performance of the organization and the employee in terms of their productivity and creativity. Performance mostly includes financial and non-financial benefits. In relation to employees, Simonin (1997) argued that social actors, who collaborate for knowledge sharing, learn more and are good at knowledge acquisition. Bierly and Chakrabarti (1996) examined firms with the same approach, and their study demonstrated that firms having in house explorers and inventors are more effective than those with exploiters and external resources.

Kalling (2003) claimed that the relationship between Knowledge Management and organizational performance not only depends on the knowledge itself but also on knowledge capitalization. Similarly, in New Zealand, Darroch (2005) noted signs of a positive relationship between the efficient utilization of Knowledge Management and the internal financial performance. Another theory established that the utilization of Knowledge Management significantly contribute in HRD practices that promote innovation and thus augments firm's performance (Inkinen, 2016). In a similar vein, it is argued that HRM practitioners develop HRM respective policies by perceiving the most desirable organizational factors and equally by positioning the most appropriate HRM models or chosen factors of these models (Andalibet al., 2019). Based on these studies and several others, it is hypothesized that Knowledge Management through social practice have a positive influence on both employees and organizational performance, which are embedded in the organizational HRD practices.

H1: Knowledge management is positively related to individual's performance

$\mathrm{H} 2$ Knowledge management is positively related to organisational performance

\section{Organizational Culture}

Knowledge Management is a contextual subject and cultural context makes an impact on it. Culture can be a combination of norms, values, views, and approaches that influence performance of an organization (Aktaset al, 2011). In their early work, Kilmannet al. (1985) described organizational culture as the values, beliefs, hopes, and behaviors that bind members together. Such organizational culture is an outcome of four dimensions adaptability, consistency, involvement, and mission. Adaptability is an organization's willingness to change its behavior, strategy, and applied procedures to follow external changes. Consistency is norms and values that remains consistent for all organizational social actors. Involvement describes the level of participation of internal social actors in decision-making, and lastly, mission represents the organizational goals and objectives.

Previous researches have shown a direct association between Knowledge Management and Organizational Culture. Researches have proven that HRD policies \& practices along with culture affect efficiency of an organization (Mathur, 2015; Rodriguez \& Stewart, 2017). Reputable studies on cultural effects have demonstrated how societal culture influences social actors' attitudes, as well as organizational performance (i.e., Kirkman \& Shapiro, 2001; Chan \& Clegg, 2002; Lok \& Crawford, 2004; Aktaset al., 2011; Huhtalaet al., 2015). The studies also indicate that organizational culture can influence HRD practices however, organizational 
performance is not so easily influenced by the employees. A recent study by Zaitouni et al. (2020) has demonstrated that the organizations which depend on continuous learning culture were more likely to achieve higher level of training success for their employees and would have consequently better HRD practices.

In context of this research, Kuwait and other Arab countries follow a collectivist society, where individuals maintain strong ties with their family members and relatives (Al-Khalifah, 2014). Such strong relationships empower social interactions and connections in forming and maintain homogeneous groups. Thus, social connections and accessibility based on social ties is a common social practice in the Arab countries, in particular. The practice is called 'Wasta'. Nevertheless, it is not necessary that 'Wasta' be practiced by other section of the society too; however, it is workable, especially when members know other members with high-rank jobs. Such practice reforms undesired distinctive source of recruitment in HRD practices. Individuals with such connections bag better jobs and education, skills, and talent are not relevant for them to fulfill the job position (Cunningham \& Sarayrah, 1994, p. 4). As a result, it can be hypothesized that an:

H3 organization's culture can influence knowledge management practice.

\section{Organizational Strategy}

Strategy is the roadmap that helps an organization in achieving their ultimate goals. Few studies have examined influence of strategy on knowledge management from various perspectives (i.e. Lyles \& Schwenk, 1992; Watkins and Marsick, 1996; Drew, 1999; Zhenget al., 2010). However, connection between strategy and Knowledge Management has been taken for granted without considering other issues such as contextual factors and individuals' social practices. Therefore, it is a necessity to consider these soft elements as the results might be surprising. Organizational strategy, in turn, directly affects organizational performance (Govin-Darajan \& Fisher, 1990).

Organizational strategy consists of four dimensions - defensiveness, futurity, proactiveness, and analysis, which drive consistent and effective, performance of organizations (Bergeron et al., 2004). The defensiveness focuses on cost reduction and efficiency enhancement within the organization (Venkatraman, 1989). Futurity emphasizes on strategic decisions and examines the long and short-term efficiency. Proactiveness represents the proactive attitude of social actors e.g., participation in decision-making processes and chasing possible developmental opportunities. Therefore, it provides creative and learning opportunities (Watkins and Marsick, 1996). Maintaining an organizational strategy that can adapt to shared practices of social actors will improve the output of the four dimensions (Bergeron et al., 2004). Therefore, HRD policies and practices should be integrated with overall organizational strategy. In rapidly growing organizations, social actors might behave differently towards a task therefore, their interaction needs to be monitored to maintain high-level organizational performance (Felin \& Knudsen, 2012). Thus, it can be concluded that:

H4: Organizational strategy is directly related to knowledge management practice.

\section{Organizational Structure}

Organizational structure is the set of components that outlines the tasks and duties of social actors. It consists of three approaches, namely formalization, centralization, and integration (Andrews \& Kacmar, 2001). Under formalization approach, organizations follow defined rules and processes and are therefore considered rigid and inflexible due to high resistance to changes and, subsequently, innovation (Andrews \& Kacmar, 2001; Robbins \& Decenzo, 2001). Such an environment encourages networking amongst social actors as an alternative means of social engagement (Robbins \& Decenzo, 2001). On the other hand, the centralization approach assumes the decision-making process to be the sole purview of the top management team (Robbins \& Decenzo, 2001; Tsai, 2002). Such an approach minimizes the involvement of lower-level social actors in the decision-making process (Sivadas \& Dwyer, 2000). In such scenarios, power lies in the hands of only a few social actors, allowing them greater autonomy.

Organizations with integrated approach focus on extending the role of social actors to ensure greater involvement in various organizational activities including delegation and knowledge sharing (Germain, 1996; Sciulli, 1998). An integrated structure strengthens social ties and thus helps social actors in increasing their output (Janz \& Prasarnphanich, 2003). Furthermore, flexible structure could support the HRD policies by encouraging employees' innovation (Jimenez-Jimenez and Sanz-Valle, 2008). It could further facilitate the employees' engagement and organizational effectiveness (Kataria et al, 2012). The relationship between HRM, work organization practices, and innovation outcomes has been reported in previous studies (Lertxundi et al., 2019). Knowledge management and integrated structure have a direct relationship and an integrated structure leads knowledge management to success (Tsai, 2002). Such a relationship increases the open communication 
between social actors and generates higher levels of creativity (Khandwalla, 1977).

The government organizations in Kuwait are not isolated from organizational structures. The majority of public sector organizations follow centralized approach. Ministries, councils, offices, bureaus, agencies, authorities, and others come under public sector. In most cases, the bureaucratic cycle includes more than one organization. Therefore, with this particular work mechanism, one might argue that while such workflow and knowledge transfer seems to be systematic in nature, it is still unable to satisfy a wide range of internal social actors, and the unique performance of HRD practices that includes both employees and organizations, is not recognized. It can therefore, be hypothesized:

H5: Applied organisational structure is positively related to knowledge management prictices.

Figure 1 represents the 5 hypotheses that are derived from the literature.

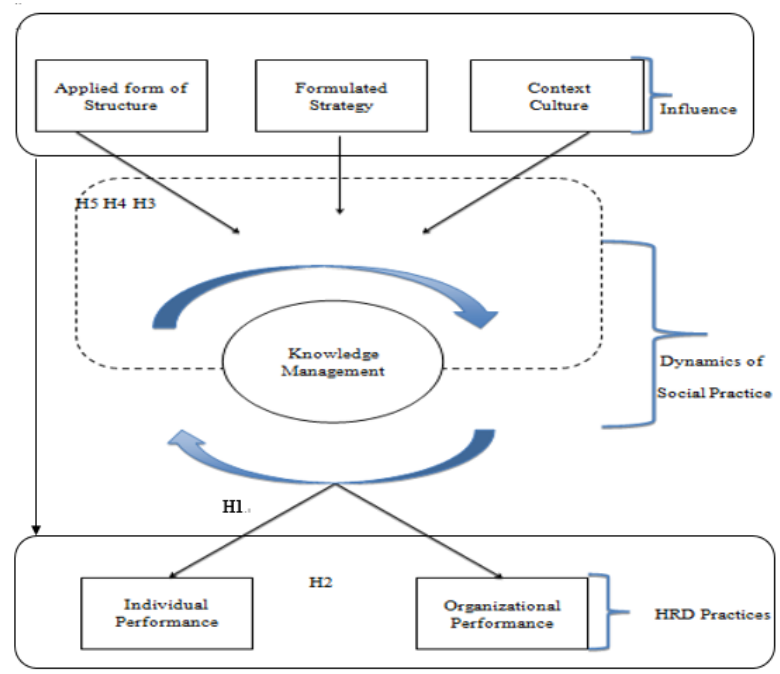

Figure 1. Hypothesized model of the study

\section{Hypothesized Model: The Role of Social Practice in the Knowledge Management Process}

This paper use social practice theory to conceptualise the hypothesis. Unlike other related theories, i.e., resource-based theory and innovation theory, have been extensively used to explore the role of Knowledge Management, the Social Practice Theory (Giddens,1984; Bourdieu,1990), offers an alternative approach, explaining how social actors interact with each other in a specific situation. In social practice, the focus is on dynamic social activities of actors with respect to their practices in a given context (Feldman and Orlikowski, 2011). Similarly, the process of learning is an intrinsically social and collective practice (Teeceet al., 1994, p.15). The practice lens has been increasingly applied into various subjects, for instance, human resources management (Khorevaet al., 2017), public administration (Kovač et al., 2016), strategic management (Jarzabkowskiet al., 2016), accounting (Grebe and Odendaal, 2017), and behavioural change (Hargreaves, 2011).

The theory of social practice has three components, namely social interaction, the duality of relations, and the mutual constitution of relations (Giddens, 1984; Bourdieu, 1990). Social interaction was viewed as the product of the various social norms that affect social actors' practices (Giddens, 1984). As for duality of relations, it was strongly argued that subjectivity and objectivity cannot be treated as separable dimensions in social practice (Bourdieu, 1990). With respect to the mutual constitution of relations component, both Giddens and Bourdieu acknowledged that social actors interact in each structure to create a set of shared practice. The fundamental assumptions of social practice make it a perfect means to understand social actors' practices in terms of their knowledge sharing and its consequent affect on their performance. In a similar vein, Brown and Duguid (2001) argued that knowledge flow is best understood by understanding how the work is practiced in reality and positioning the knowledge concept as a natural output of the real interactions between individuals. Based on the above background and theory, Figure 1 presents hypothesized model to reflect mediating role of knowledge management between organizational elements and relevant performance. 


\section{Methodology}

\subsection{Population and Sampling Technique}

Since this study is exploratory in nature, to understand how knowledge management is manifested between organizational characteristics and its performance, along with its employees by revealing their social practice, a quantitative approach was adopted. Adopting a multiple case-based approach, the paper conducted 478 surveys in five public organizations in Kuwait. The sample was drawn from participants from both top and middle management in HRM division and other departments. It also included relevant frontline employees as they are believed to have acquired the relevant knowledge, experience, and skills to provide significant answers to the research queries (Saunders et al., 2016), and provide a realistic view on the inorganization's current culture and procedures. Therefore, we adopted the cluster sample technique as it is associated with an easily accessible population rather than individual population (Saunders et al., 2016). Furthermore, this sample technique allows a far greater geographical concentration than other quantitative sampling techniques (Bryman, 2016).

\subsection{Data Collection Procedure}

The fieldwork was carried out in Kuwait for a period of four months. The survey used in this research was self-administrated. The questionnaire was in English and Arabic languages in order to reach a wider range of managers. For validity purpose, two experts reviewed the questionnaires to ensure the questions had the same meaning in each language (Hazzi \& Maldaon, 2015). Prior to the distribution of the survey, an official letter was sent to the relevant departments in each organization for approval. Due to cultural limitations drop-off and pick-up method was used to collect the questionnaire, as it's a common and effective technique in Kuwait. Upon gaining the approval, a pilot survey was conducted before the main survey. 15 samples were distributed and post the pilot survey some terms were clarified, and two questions were removed. After the amendments, a total of 590 questionnaires were distributed, of which 489 were returned; 11 were subsequently removed as the response was incomplete. Therefore, only 478 samples were found to be appropriate for final analysis. The response rate of valid surveys is shown in Table 1. Furthermore, ethical approval was taken prior to the distribution of the questionnaire to comply with the research's ethical guidelines, and participants were assured anonymity.

Table 1. Survey response condition

\begin{tabular}{ll}
\hline Description & Number \\
\hline Surveys sent & 590 \\
Surveys received & 489 \\
Invalid and incomplete samples & 11 \\
Valid samples & 478 \\
Response rate for valid samples & $81.01 \%$ \\
\hline
\end{tabular}

\subsection{Data Analysis Procedure}

Upon collecting the questionnaires, the data was analysed using SPSS version 23 in parallel with the PLS software. A series of statistical tests were conducted to ensure rigour and meaningful interpretation of the data collected. This process began with reliability testing using the Cronbach's alpha coefficient to assess the consistency of the responses. This step is also known as testing the internal consistency or inter-item reliability (Cronbach, 1951, 2004). Furthermore, Cronbach's alpha remains the most widely and frequently used reliability index (Sijtsma, 2009). Six variables of the hypothesized model are measured through their respective items. Culture is measured through 3, Strategy 4, Structure 4, Knowledge Management 2, Employee Performance 2 and Organization Performance 5.

Given the probability of obtaining the observed results if the null hypothesis (the frequency of observations is equal across all groups) is true, in most social science research, a result is considered statistically significant if this value is $\leq 0.05$. Cronbach alpha coefficients were evaluated using the guidelines suggested by George and Mallery (2016), according to which alpha value $>0.9$ is excellent, $>0.8$ is good, $>0.7$ is acceptable, $>0.6$ is questionable, $>0.5$ is poor, and $\leq 0.5$ is unacceptable. The components used to measure Knowledge Management had a Cronbach's alpha coefficient of 0.94 , indicating excellent reliability.

The hypothesised model is operationalised to establish a robust measurement. Structural Equation Modelling (SEM) approach was adopted using the Partial Least Squares (PLS) software version 2.0 M3. PLS structural equation analysis relatively requires a small sample size (Marcoulides et al., 2009). PLS is a powerful technique 
which simultaneously assesses the reliability and validity of the measures of the theoretical constructs and, consequently, allows an estimate of the associations among these constructs (Wold, 1982). Furthermore, the technique provides solutions to multiple regression problems (Wold et al., 1984) and was developed for modelling information-scarce scenarios in the social sciences (Wold, 1975, 1982). Thus, the PLS technique has been widely adopted by researchers from various disciplines including, strategic management (Hulland, 1999), marketing (Reinartz et al., 2004; Henseler et al., 2009), organizational behavior (Higgins et al., 1992), consumer behavior (Fornell \& Robinson, 1983), and information systems (Ahuja et al., 2003). A satisfactory evaluation of the structural model in PLS must consist of two indexes including the squared multiple correlations (R-Squared), path coefficients, and t-value (Mokhber et al., 2015). R-Squared, which will be calculated for the dependent latent variable, has threshold values of $0.25,0.5$ and 0.7 which are often used to describe a weak, moderate, and strong coefficient of determination, respectively (Hair et al., 2013). If a certain model path's inner structure explains an endogenous latent variable with only a few latent exogenous variables (one or two, for instance), a moderate R-Squared is considered acceptable (Henseler et al., 2009). See next section for the result.

As part of reporting the measurements, the analysis is started with the descriptive statistics (see Table 1), to understand the attributes of the data followed by Skewness and Kurtosis to evaluate the normal distribution of data set. Afterwards, results of Pearson's Correlation analysis was applied because the data measured by the questionnaire was ordinal and dependent on a specified scale. The measurement model was evaluated by assessing the convergent validity, which is measured by factor loading the average variance extracted (AVE), and the composite reliability (CR) result. reports the item loadings, AVE, CR, and R-Squared. Finally, the causalities among the variables are measured through T-Values. Moreover, mediation was conducted to confirm whether the mediator variable explains the relationship between two continuous variables (independent and dependent variables) or otherwise. Thus, Baron and Kennys' method of establishing mediation was adopted to examine the mediation through a series of regressions (Baron \& Kenny, 1986).

\section{Results and Interpretations}

The participants' demographic details are presented in Table 2 as frequencies of nominal variables. The most frequently observed category of gender was male $(n=250,52 \%)$. Furthermore, frontline employees represented the majority in this study $(\mathrm{n}=392,82 \%)$. In terms of education, maximum participants held a bachelor's degree $(\mathrm{n}=249,52 \%)$. And, most of the participants had 11 to15 years of experience $(\mathrm{n}=159,33 \%)$.

Table 2. Frequency table for nominal variables

\begin{tabular}{lll}
\hline Variable & $n$ & $\%$ \\
\hline Gender & & \\
Female & 228 & 48 \\
Male & 250 & 52 \\
Job & & \\
Executive Managers & 8 & 2 \\
Middle Managers & 78 & 16 \\
Front line Employees & 392 & 82 \\
Education & & \\
High school & 52 & 11 \\
Diploma & 145 & 30 \\
Bachelor & 249 & 52 \\
Higher education & 32 & 7 \\
Age Group & & \\
Less than 25 & 212 & 44 \\
From 25 to 35 & 184 & 38 \\
From 36 to 45 & 67 & 14 \\
More than 45 & 15 & 3 \\
Experience & & \\
Less than 5 years & 58 & 12 \\
From 6 to 10 years & 120 & 25 \\
From 11 to 15 years & 159 & 33 \\
More than 15 years & 141 & 29 \\
\hline
\end{tabular}


As for the interval and ratio variables, as shown in Table 3, it may be concluded that the mean average of the data $(\mu)$ for all the study variables ranged from 3.04 to 3.51 , which reflected the clarity of the questionnaire with the threshold point being 3 and above. Moreover, the information presented in Table 3 demonstrates that the questionnaire was normally distributed. This was because the Skewness values ranged from -0.49 to 0.05 , and the Kurtosis values ranged from -0.53 to 0.27 . As stated by Westfall and Henning (2013), when the Skewness value is $\geq 2$ or $\leq-2$, then the variable is considered to be asymmetrical about its mean; furthermore, if the Kurtosis value is $\geq 3$, then the distribution of the associated variables does not produce outliers. On such occasions, and based on the figures, no further tests were required to establish normalcy.

Table 3. Summary statistics table for interval and ratio variables

\begin{tabular}{|c|c|c|c|c|c|c|c|}
\hline Variable & $M$ & $S D$ & $N$ & Min. & Max. & Skewness & Kurtosis \\
\hline Culture & 3.43 & 0.77 & 478 & 1.00 & 5.00 & 0.00 & -0.53 \\
\hline Strategy & 3.51 & 0.88 & 478 & 1.00 & 5.00 & -0.49 & -0.25 \\
\hline Structure & 3.04 & 0.90 & 478 & 1.00 & 5.00 & 0.01 & -0.52 \\
\hline $\begin{array}{l}\text { Knowledge } \\
\text { Management }\end{array}$ & 3.27 & 0.68 & 478 & 1.00 & 5.00 & 0.05 & -0.12 \\
\hline $\begin{array}{l}\text { Individual } \\
\text { Performance }\end{array}$ & 3.38 & 0.58 & 478 & 1.80 & 5.00 & 0.01 & 0.27 \\
\hline $\begin{array}{l}\text { Organizational } \\
\text { Performance }\end{array}$ & 3.46 & 0.67 & 478 & 1.67 & 5.00 & -0.18 & 0.07 \\
\hline
\end{tabular}

Pearson's Correlation analysis was applied in this study because the data measured by the questionnaire was ordinal and dependent on a specified scale (See Table 4). Thus, Pearson's Correlation analysis was applied on six variables -culture, strategy, structure, knowledge management, individual performance, and organizational performance. The analysis was vital to the study as it measured the linear relationship between two given factors and reflected the relevant association between them. Cohen's standard was further used to evaluate the strength of the relationships, where coefficients between 0.10 and 0.29 represent a small-sized effect, coefficients between 0.30 and 0.49 represent a moderate-sized effect, and coefficients above 0.50 indicate a large-sized effect (Cohen, 1988).

The results of the Pearson's Correlation analysis indicated that there was a significant positive relationship and a large association between KM and HRD practices, that is between Knowledge Management and Individual Performance, as well as between Knowledge Management and Organizational Performance $\left(r_{\mathrm{p}}=0.63, p<0.001\right.$, and $r_{\mathrm{p}}=0.72, p<0.001$, respectively). This, in turn, reflects that the KM process helps in raising the overall performance of both the social actors and the organization. The results also revealed a significant positive relationship and a consequent large association between individual performance and organizational performance, that is between HRD practices and relevant performance. This is further justifiable because the overall organizational performance is a natural product of the collective individual performances and, therefore, they are mutually inclusive and dependent on each other. The complete list of correlations between the study factors is shown in Table 4. Figure 2 illustrates a scatterplot matrix of correlations.

Table 4. Pearson's correlation matrix among culture, strategy, structure, knowledge management, individual performance, and organizational performance

\begin{tabular}{|c|c|c|c|c|c|c|}
\hline Variable & 1 & 2 & 3 & 4 & 5 & 6 \\
\hline 1. Culture & - & & & & & \\
\hline 2. Strategy & 0.77 & - & & & & \\
\hline 3. Structure & 0.66 & 0.77 & - & & & \\
\hline $\begin{array}{l}4 . \quad \text { Knowledge } \\
\text { Management }\end{array}$ & 0.51 & 0.59 & 0.63 & - & & \\
\hline $\begin{array}{ll}5 . & \text { Individual } \\
\text { Performance } & \end{array}$ & 0.50 & 0.60 & 0.64 & 0.63 & - & \\
\hline $\begin{array}{l}6 . \quad \text { Organizational } \\
\text { Performance }\end{array}$ & 0.61 & 0.71 & 0.70 & 0.71 & 0.72 & - \\
\hline
\end{tabular}

Note. The critical values are $0.09,0.12$, and 0.15 for significance levels $0.05,0.01$, and 0.001 respectively. 

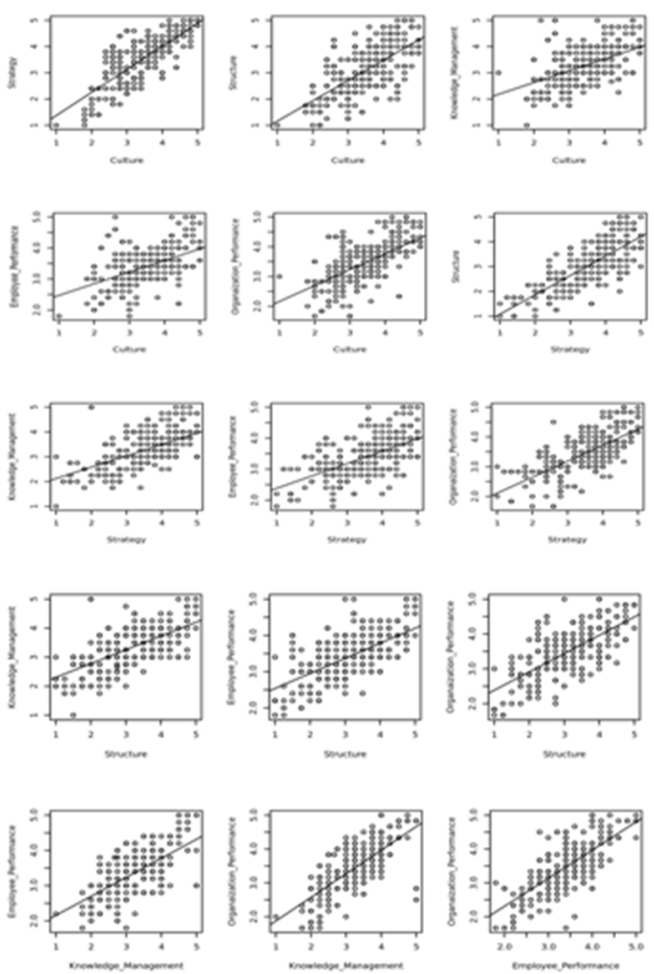

Figure 2. Scatterplot Matrices between Structure, Strategy, Culture, Knowledge Management, Employee Performance, and Organizational Performance

\subsection{Results for the Measurement Model}

The measurement model was evaluated by assessing the convergent validity, which is measured by factor loading the average variance extracted (AVE), and the composite reliability (CR) result. This step is a prerequisite to the PLS analysis. For the convergent validity, study variables and relevant questions should have a loading value above the recommended threshold, which is 0.5 (Hair et al., 2006). Therefore, any item with a value of less than 0.5 was dropped. This rule was applicable to one item from the structure variable and two items from the knowledge management variable. The results of the construct loading revealed good item loading above the recommended threshold. As for the composite reliability (CR), the results showed all constructs exceeded the minimum threshold of 0.7. Similarly, the result of the average variance extracted (AVE) shows that the values of the constructs were above the recommended threshold value of 0.5 (Hair et al., 2006). Table 5 reports the item loadings, AVE, CR, and R-Squared. 
Table 5. Summary of constructs item loadings, AVE, CR, and R-Squared

\begin{tabular}{llllll}
\hline Construct & Indicator & Loadings & CR & AVE & R-Squared \\
& CUL1 & 0.774 & & & \\
Culture & CUL2 & 0.820 & 0.851 & 0.655 & \\
& CUL3 & 0.833 & & & \\
& ST1 & 0.870 & & & \\
Strategy & ST2 & 0.916 & & & \\
& ST3 & 0.829 & 0.927 & 0.652 & \\
& ST4 & 0.871 & & & \\
Structure & STRU1 & 0.621 & & & \\
& STRU2 & 0.872 & & & \\
Knowledge Management & STRU3 & 0.859 & 0.880 & 0.761 & \\
& STRU4 & 0.851 & & & \\
KM1 & 0.912 & & & \\
& KM2 & 0.913 & 0.909 & 0.833 & 0.524 \\
& EP1 & 0.898 & & & \\
& EP2 & 0.909 & 0.899 & 0.817 & 0.416 \\
& OP1 & 0.721 & & & \\
& OP2 & 0.828 & & & \\
Organization Performance & OP3 & 0.701 & 0.868 & 0.569 & \multirow{2}{*}{0.531} \\
& OP4 & 0.698 & & & \\
& OP5 & 0.815 & & & \\
\hline
\end{tabular}

In order to test the constructs' convergent and discriminant validity, Zainudin (2014) suggested that the correlation between constructs must be lower than a threshold value of 0.85 and, simultaneously, must be lower than the square root of the AVE to establish a discriminant validity of the construct. With respect to the statistical results of this research, a comparison of the correlation with the square root of the AVE indicates that the correlation between constructs is less than the square root of the AVE. This, in turn, indicates that the results of the analysis support the adequate convergent and discriminant validity of the model constructs, as shown in Table 6.

Table 6. Latent variable inter-correlation, and the square root of the AVE for assessing convergent and discriminant validity of the model constructs

\begin{tabular}{llllllr}
\hline Constructs & Culture & $\begin{array}{l}\text { Employee } \\
\text { Performance }\end{array}$ & $\begin{array}{l}\text { Knowledge } \\
\text { Management }\end{array}$ & $\begin{array}{l}\text { Organization } \\
\text { Performance }\end{array}$ & & \\
\hline Culture & 0.809 & & & & \\
Individual Performance & 0.532 & 0.904 & & & \\
Knowledge Management & 0.584 & 0.646 & 0.913 & & \\
Organizational & & & 0.729 & 0.755 & \\
Performance & 0.660 & 0.722 & 0.648 & 0.702 & 0.872 & \\
Strategy & 0.788 & 0.611 & 0.704 & 0.721 & 0.754 & 0.807 \\
Structure & 0.736 & 0.645 & Struc & \\
\hline
\end{tabular}

Note. The diagonal elements (in bold) are the square roots of Average Variance Extracted. Other non-diagonal elements are latent variable correlations". 


\subsection{Results of the Structural Model and Hypotheses}

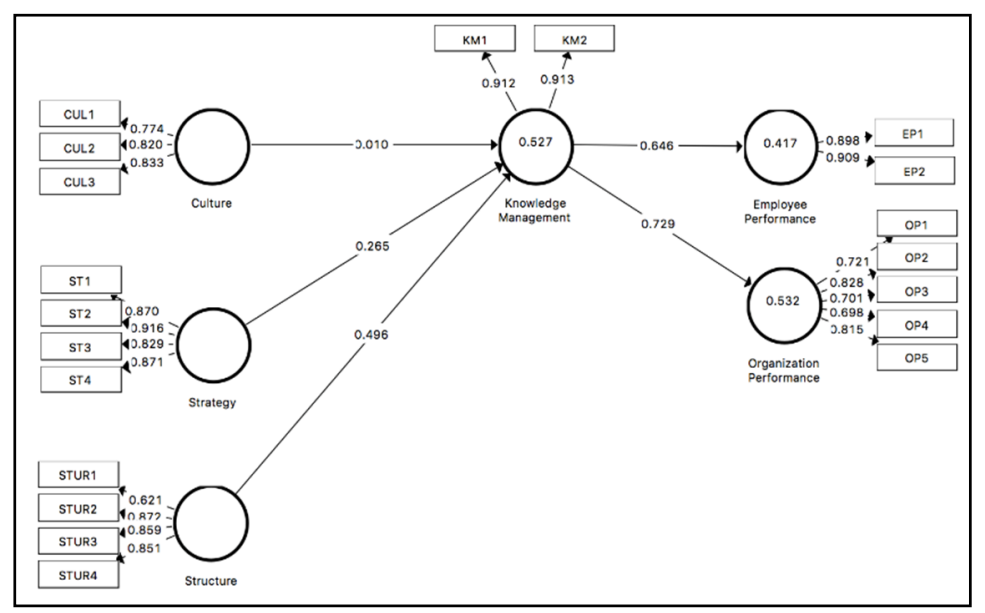

Figure 3. The structural equation model for the study

In this study, the R-Squared for the knowledge management variable was moderate, with a value of 0.524 , which meant that the Culture, Strategy and Structure variables explained about $72 \%$ of the variance of the organizational performance via mediating role of KM. Equally, the R-Squared for organizational performance was moderate, as its value was 0.532 , which meant that culture, strategy, and structure explained about $73 \%$ of the variance of organizational performance. The R-Squared for employee performance was also moderate, 0.417 , which meant that culture, strategy, and structure explained about $64 \%$ of the variance of employee performance via the mediating role of KM.

Another indicator allowing the evaluation of the PLS are the path coefficients of the constructs. In this regard, Chin (2010) argued that to demonstrate a meaningful predictive power using a PLS model, the analysis of the standardized paths needs to be close to a value of 0.20 or higher. Finally, T-values, as another indicator, were obtained through the bootstrap routine and must be greater than 1.96 (Chin, 1998). These popular figures are in line with the results of this study, as the R-Squared results, the path coefficient, and t-values, fit in with the recommended threshold values. Therefore, it can be concluded that the model used in this study had an excellent predictive power, which can explain the mediating role that knowledge management has between organizational characteristics, including structure, strategy, and culture, and individual along with organizational performance. The results of the structural model, along with the hypotheses, are justified in Figure 3.

Further to the analysis of the PLS, hypothesis testing was also conducted to analyze the cause-effect relationships (causality) between the six study variables in the model, based on t-stat values. As previously argued, T-values must be greater than 1.96 in order to predict a significant association between the study variables (Chin, 1998). With respect to this study, five hypotheses were formed, of which four were found to be significant; therefore, the supported hypotheses were $1,2,4$, and 5 only.

According to the results presented in Table 7, knowledge management was positively related to individual performance (Hypothesis 1). Similarly, knowledge management was positively related to organizational performance (Hypothesis 2). Therefore, KM was positively related to the adopted HRD practices in the public sector organizations. However, the results revealed that context culture was negatively associated with KM (Hypothesis 3). Formulated strategy was found to have a positive association with KM (Hypothesis 4). Likewise, the applied organizational structure was positively related to KM (Hypothesis 5). 
Table 7. Summary of the hypotheses testing

\begin{tabular}{|c|c|c|c|c|c|c|c|c|}
\hline & & & $\begin{array}{l}\text { Original } \\
\text { Sample }(\mathrm{O})\end{array}$ & $\begin{array}{l}\text { Sample } \\
\text { Mean (M) }\end{array}$ & $\begin{array}{l}\text { Standard Error } \\
\text { (STERR) }\end{array}$ & $(|\mathrm{O} / \mathrm{STERR}|)$ & $\begin{array}{l}\mathrm{P} \\
\text { Values }\end{array}$ & $\begin{array}{l}\text { Hypothesis } \\
\text { Testing }\end{array}$ \\
\hline $\begin{array}{l}\mathrm{H} 1: \text { Knowledge } \\
\text { Individual Perfo }\end{array}$ & \multicolumn{2}{|c|}{ Management -> } & 0.646 & 0.643 & 0.029 & 22.076 & 0.000 & Supported \\
\hline $\begin{array}{l}\mathrm{H} 2 \text { : Knowledg } \\
\text { Organizational } \mathrm{P}\end{array}$ & $\begin{array}{r}\text { Ma } \\
\text { erforn }\end{array}$ & $\begin{array}{l}\text { agement } \quad-> \\
\text { ance }\end{array}$ & 0.729 & 0.730 & 0.030 & 24.160 & 0.000 & Supported \\
\hline $\begin{array}{l}\text { H3: Culture } \\
\text { Management }\end{array}$ & & Knowledge & 0.010 & 0.017 & 0.063 & 0.160 & 0.873 & Not Supported \\
\hline $\begin{array}{l}\text { H4: Strategy } \\
\text { Management }\end{array}$ & & Knowledge & 0.265 & 0.262 & 0.074 & 3.570 & 0.000 & Supported \\
\hline $\begin{array}{l}\text { H5: Structure } \\
\text { Management }\end{array}$ & & Knowledge & 0.496 & 0.494 & 0.047 & 10.463 & 0.000 & Supported \\
\hline
\end{tabular}

\section{Discussion}

The current study extends the literature on KM in four different ways. First, it introduces the importance of the mediating role of KM as a vital part of internal social actors' daily practice. Second, it simultaneously tests the impact of organizational characteristics including structure, strategy, and culture on relevant HRD practices that influences both individual and organizational performance through the mediating role of knowledge management. Third, it provides empirical answers on why KM is considered a context-specific discipline which needs attention of organizational decision makers. Fourth, it pushes the boundaries further by expanding our understanding of the dynamics of social practice in relation to the knowledge sharing process.

The aim of this study was to test a model of KM to investigate how various organizational characteristics affect HRD practices and relevant performances. The results supports the proposed hypnotized model and, for the majority of the hypnotized relationships. The results showed that a significant predictor in KM process is an insight that participation in knowledge sharing enhances both individual, as well as organizational, performance. The results were also consistent with previous research in knowledge management, providing additional evidence that some organizational characteristics affect performance through the mediating role of knowledge management (Fugate et al., 2009; Kiessling et al., 2009; Zheng et al., 2010) or direct effect of knowledge management on performance (Choi et al., 2008), and on adopted HRD practices (Chuang et al., 2016).

The results further suggest that the performance of internal social actors informs the performance of their organization to a significant extent. Both levels of performance were affected by the mediating role of knowledge management, which indicated that social actors should be engaged extensively in social networks to achieve higher productivity. The social networks engaged in by social actors affect the ability to reach a shared level of knowledge in terms of organizational strategy and structure. Shared knowledge and open-door policy helped in enhancing the performance of both individuals and organizations. The conclusions drawn by Jarzabkowski (2005), who argued that within the practice perspective, organizational strategy is viewed as a situated and socially accomplished activity, reflects the same

The study also provides substantial evidence of knowledge management as a predictor and its links with characteristics of organization and performance. Based on the Pearson Correlation analysis shown in Table 3, all hypotheses were significantly associated with individual and organizational performance and productivity. Knowledge Management construct and social actors' performance were correlated in this research $(r=0.63, p<$ $0.001)$. Likewise, knowledge management and organizational performance were highly correlated $(\mathrm{r}=0.71, \mathrm{p}<$ 0.001). This further indicates that the more the knowledge sharing, the greater the performance. Such alignment needs mutual integration between business strategy and relevant HRM policies \& practices in public sector organizations. The same was observed by Powell et al. (2011), who emphasized the importance of aligning both individual and group-level cognition for a better organizational fit. A potential explanation for this alignment is that the internal social actors should be actively engaged in the knowledge management process to ensure better results. In a similar vein, Ukil and Akkas (2017) found that the involvement of middle managers in the workflow process can bridge the information gap between the top-level management and front-line staff.

The findings of this study are in line with the outcomes determined by Torabi et al. (2016), which reflects the positive relationship between organizational culture, strategy and structure of HRD practices, which influences both employee and organizational performance. This may further suggest that knowledge management does not necessarily entail a material factor that impacts organizational performance, rather social practice instrument 
which is strongly associated with shaping the foundation of organizational culture, strategy and structure and its consequent impact on performance. However, an interesting finding of this research, based on the chosen context, was that the effect of the context culture on knowledge management practice was not supported due to its $\mathrm{P}$ value $=0.873$ (See Table 6). Although KM is seen as a key mechanism in predicting the social actors' practice, the context culture was the only organizational element which was not influenced by KM practices. This was contrary to the findings of Zheng et al. (2010), who found that knowledge management fully meditated influence of organizational culture on organizational effectiveness.

This interesting finding suggests that lower level of knowledge sharing in public sector organizations is strongly associated with strong cultural roots, beliefs, perceptions, and rituals of internal social actors. The influential role of the cultural context on an organization's settings cannot be ignored within management studies as the culture reflects the associated shared assumptions, values, norms, and beliefs (Schein, 1985). The culture has a huge impact on knowledge management more than other elements of organizations that were examined. Within the social practice lens, Bourdieu (1990) stated that "an interaction between two agents or groups of agents endowed with the same habitus (Say A and B), everything takes place as if each one's action(Say a1 for A) was organized in reference to the reactions which they call forth from any agent possessing the same habitus (say b1 for B)" (p. 61). Such interpretation raises awareness of the social actors' norms and beliefs, which regulates their attitudes towards performance. Furthermore, this finding brings to our attention the importance of promoting an organizational cultural spirit in public sector organizations where social actors are willing to learn and adapt to rapid change. Moreover, this emphasizes the vital role of leaders in public sector organizations to align the organizational culture with the relevant HRM policies and mitigate the tension between the two constructs.

Finally, the findings of this research prove that adopting a control mechanism, which is not directly influenced by actors' social practice, will help in ensuring positive outcomes for organizations. The social practice of individuals will be guided by the formal procedure that controls the interrelationship of both individuals and organizational settings. A reliable explanation for such interactions can be drawn from Bourdieu (1990) as he argued that 'the structures characterizing a determinant class of conditions of existence produce the structures of the habitus, which in turn are the basis of the perception and appreciation of all subsequent experiences' (p. 54). This in turn reflects the importance of not just the settings of the organizations, but also the corporation and shared understanding between the various social actors that is based on the spirit of public service and interest.

\section{Conclusion}

The aim of this study was to test a Knowledge Management model to investigate how organizational characteristics including strategy, structure, and culture can affect HRD practices and relevant performance. Although many organizations still believe that providing new software programs without suitable reflection upon the organization's characteristics is enough to guarantee successful organizational performance, results of the study have demonstrated the opposite. Our research provides an alternative approach to Knowledge Management practice by reflecting on the significance of creating a knowledge-friendly atmosphere that aligns organizational settings and HRD practices with relevant performance. The findings also suggest that knowledge management is, in the first instance, a social practice that cannot not be separated from internal social actors, nor treated as an isolated object. The association highlights the importance of providing supportive tools to promote the knowledge sharing practices that benefit individual, as well as organizational, performance.

Therefore, leaders should aim to raise the team work spirit and employees' engagement in decision-making process at public sector organizations by encouraging communication and open door policies. The decision-makers should also stress on cultural values of the employee by encouraging knowledge sharing through various organizational activities including seminars, coaching, mentoring, and internal role plays. Moreover, as it is evident that knowledge sharing affects HRD practices including staff and organizational performance, leaders should focus on providing clarity to their employees by clarifying their roles and responsibilities, managing their expectations, and communicating the evaluation criteria. Also, on the basis of the findings, it is logical to suggest that public sector organizations should focus on training and development of the employee and helping them develop a career path. In addition, employees at various organizational levels need to be engaged in strategy formulation to facilitate archiving and executing various organizational objectives. The suggestions would be relevant only if HRD policies and procedures are empowered and a greater autonomy is awarded to relevant leaders.

The correlations between the characteristics of organizations and performance reflect the importance of regulating individuals' social practices through characteristics discussed above. Finally, it is worth noting that the study has been the first to quantitatively examine the mediating role of Knowledge Management in assessing 
how organizational characteristics can affect HRD practices, including both individuals and organizational performances, simultaneously. Such exploration was also unique in terms of alternating interpretation that was provided based on the lens of social practice. Knowledge sharing is not a rigid factor by its own, it is rather a social practice of the daily interactions of its internal social actors. Furthermore, shared knowledge and social practice is highly context-driven and are symbolized by organizational rituals, values, and beliefs of members which further influences the overall organizational performance. Therefore, our study makes a vital contribution to the under-researched area of Knowledge Management based on individuals' social interactions.

\section{Directions for Future Research}

We recommend that future research focus on Knowledge Management in different ways. For instance, our research was based on the internal environment, and the fact that business environment is dynamic in nature and requires extensive social interactions among various levels of actors, future research can explore how the discipline of Knowledge Management can be aligned with the internal and the external environments. Second, further studies should integrate literature on Knowledge Management and apply strategy-as-practice lens to gain inclusive insight into such a dynamic topic. This research was conducted in public sector domain, while future research can include the private and voluntary sectors, and examine the same hypothesized association provided to facilitate direct comparison between the three. Another important suggestion is that Knowledge Management has room for adopting qualitative data with respect to the hypothesized association to gain deeper insights into individuals' social interactions. Finally, future research can focus on HRD practices in public sector organizations to gain better insights into relevance of alignment of HRM policies \& practices with the organizational strategy.

\section{References}

Ahuja, M., Galletta, D., \& Carley, K. (2003). Individual centrality and performance in virtual r\&d groups: An empirical study. Management Science, 49(1), 21-38. https://doi.org/10.1287/mnsc.49.1.21.12756

Al-Ajami, A., \& Al-Qa'eed, M. (2020). The Impact of Knowledge Management on the Marketing Performance of Small and Medium Enterprises in the State of Kuwait. Modern Applied Science, 14(6), 21-28. http://doi.org/10.5539/mas.v14n6p21

Alajmi, B., Marouf, L., \& Chaudhry, A. (2015). Knowledge Management (KM) Practices - A Study of KM Adoption among Doctors in Kuwait. International Journal of Business, Human and social sciences, 8(1), 128-134. http://doi.org/10.5281/zenodo.1337926

Alavi, M., \& Leidner, D. (2001). Knowledge management and knowledge management systems: Conceptual foundations and research issues. MIS Quarterly, 25(1), 107-136. http://doi.org/10.2307/3250961

Allameh, S. M., \& Zare, S. M., \& Davoodi, S. M. R (2011). Examining the impact of KM enablers on knowledge management processes. Procedia Computer Science, 3(2011), 1211-1223. https://doi.org/10.1016/j.procs.2010.12.196

Al-Qarioti, M. (2015). The impact of knowledge management on organizational performance: An empirical study of Kuwait University. Eurasian Journal of Business and Management, 3(4), 36-54. http://doi.org/10.15604/ejbm.2015.03.04.004

Andalib, T., Darun, M., \& Azizan, N. (2019). East Asian trends of human resource management: theories and practices. International Journal of Human Resources Development and Management, 19(2), 135-149. https://doi.org/10.1504/IJHRDM.2019.10018448

Andrews, M., \& Kacmar, K. (2001). Discriminating among organizational politics, justice, and support. Journal of Organizational Behavior, 22(4), 347-366. https://doi.org/10.1002/job.92

Baron, R., \& Kenny, D. (1986). The moderator-mediator variable distinction in social psychological research: Conceptual, strategic, and statistical considerations. Journal of Personality and Social Psychology, 51(6), 1173-1182. https://doi.org/10.1037/0022-3514.51.6.1173

Bergeron, F., Raymond, L., \& Rivard, S. (2004). Ideal patterns of strategic alignment and business performance. Information and Management 41(8), 1003-1020. https://doi.org/10.1016/j.im.2003.10.004

Bierly, P., \& Chakrabarti, A. (1996). Generic knowledge strategies in the US pharmaceutical industry. Strategic Management Journal, 17(S2), 123-135. https://doi.org/10.1002/smj.4250171111

Bourdieu, P. (1990). The Logic of Practice. Cambridge, Polity Press.

Brockman, B. K., \& Morgan, R. M. (2003). The role of existing knowledge in new product innovativeness and 
performance. Decision Sciences, 34(2), 385-419. https://doi.org/10.1111/1540-5915.02326

Brown, J. S., \& Duguid, P. (2001). Knowledge and organization: A social-practice perspective. Organization Science 12(2), 198-213. https://doi.org/10.1287/orsc.12.2.198.10116

Bryman, A. (2016). Social Research Method (5th ed.). Oxford: Oxford University Press.

Chan, A., \& Clegg, S. (2002). History, culture and organization studies. Culture and Organization, 8(4), $259-273$.

Chiabrishvili, M., \& Zaim, H. (2018). The role of knowledge management for long-term sustainability in Kuwait companies. Middle East Journal of management, 5(4), 340-355. https://doi.org/10.1504/MEJM.2018.095586

Choi, B., \& Lee, H. (2002). Knowledge management strategy and its link to knowledge creation process. Expert Systems with Applications, 23(3), 173-187. https://doi.org/10.1016/S0957-4174(02)00038-6

Choi, B., Poon, K. S., \& Davis, J. G. (2008). Effects of knowledge management strategy on organizational performance: A complementarity theory-based approach. Omega, 36(2), 235-251. https://doi.org/10.1016/j.omega.2006.06.007

Chuang, C., Jackson, S., \& Jiang, Y. (2016). Can knowledge-intensive teamwork be managed? Examining the roles of HRM systems, leadership, and tacit knowledge. Journal of Management, 42(2), 524-554. https://doi.org/10.1177/0149206313478189

Cohen, J. (1988). Statistical power analysis for the behavior sciences (2nd ed.). St. Paul, MN, West Publishing Company.

Cronbach, L. (1951). Coefficient alpha and the internal structure of tests. Psychometrika, 16(3), 297-334. https://doi.org/10.1007/BF02310555

Cronbach, L. (2004). My current thoughts on coefficient alpha and successor procedures. Educational and Psychological Measurement, 64(3), 391-418. https://doi.org/10.1177/0013164404266386

Cunningham, R., \& Sarayrah, Y. (1994). Taming Wasta to achieve development. Arab Studies Quarterly, 16(3), 29-41. https://doi.org/10.22452/ajba.vol13no1.7

Darroch, J. (2005). Knowledge management, innovation and firm performance. Journal of Knowledge Management, 9(3), 101-115. https://doi.org/10.1108/13673270510602809

Darroch, J., \& McNaughton, R. (2002). Examining the link between knowledge management practices and types of innovation. Journal of Intellectual Capital, 3(3), 210-222. https://doi.org/10.1108/14691930210435570

Davenport, T., Prusak, L. (1998). Working knowledge: How organizations manage what they know. Harvard Business Press.

Drew, S. (1999). Building knowledge management into strategy: making sense of a new perspective. Long Range Planning, 32(1), 130-136. https://doi.org/10.1016/S0024-6301(98)00142-3

Dzenopoljac, V., Alasadi, R., Zaim, H., \& Bontis, N. (2018). Impact of knowledge management processes on business performance: Evidence from Kuwait. The Journal Of Corporate Transformation, 25(2), 77-87. https://doi.org/10.1002/kpm.1562

Elmorshidy, A. (2018). The impact of knowledge management systems on innovation: An empirical investigation in Kuwait. Journal of Information and Knowledge Management Systems, 48(3), 388-403. https://doi.org/10.1108/VJIKMS-12-2017-0089

Feldman, M., \& Orlikowski, W. (2011). theorizing practice and practicing theory. Organization Science, 22(5), 1240-1253. http://doi.org/10.1287/orsc.1100.0612

Felin, T., \& Knudsen, T. (2012). A theory of nascent entrepreneurship and organization. Managerial and Decision Economics, 33, 409-426. https://doi.org/10.1002/mde.2557

Felin, T., Foss, N. J., \& Ployhart, R. E. (2015). The micro-foundations movement in strategy and organization theory. The Academy of Management Annals, 975-632. https://doi.org/10.5465/19416520.2015.1007651

Fornell, C., \& Robinson, W. (1983). Industrial organization and consumer satisfaction/dissatisfaction. Journal of Consumer Research, 9(4), 403-412. https://doi.org/10.1086/208934

Fugate, B., Stank, T., \& Mentzer, J. (2009). Linking improved knowledge management to operational and 
organizational performance. Journal of Operations Management 27(3), 247-264. https://doi.org/10.1016/j.jom.2008.09.003

George, D., \& Mallery, P. (2016). SPSS for Windows step by step: a simple guide and reference 11.0 update (14th ed.). Boston, MA. Allyn and Bacon.

Germain, R. (1996). The role of context and structure in radical and incremental logistics innovation adoption. Journal of Business Research, 35(2), 117-127. https://doi.org/10.1016/0148-2963(95)00053-4

Giddens, A. (1984). The constitution of society: Outline of the theory of structuration. Cambridge. Polity Press.

Gold, A., \& Malhotra, A. A. (2001). Knowledge management: An organizational capabilities perspective. Journal of Management Information $\quad$ Systems, $\quad 18(1), \quad 185-214$. https://doi.org/10.1080/07421222.2001.11045669

Gope, S., Elia, G., \& Passiante, G. (2018). The effect of HRM practices on knowledge management capacity: a comparative study in Indian IT industry. Journal of Knowledge Management, 22(3), 649-677. https://doi.org/10.1108/JKM-10-2017-0453

Gourlay, S. (2001). Knowledge Management and HRD. Human Resource Development International, 4(1), 27-46. https://doi.org/10.1080/13678860121778

Grebe, L., \& Odendaal, E. (2017). Accounting research, education and practice: A social practice theory perspective. Southern African Journal of Accountability and Auditing Research 19(1), 147-156.

Grover, V., \& Davenport, T. (2001). General perspectives on knowledge management: fostering a research agenda. Journal of Management Information Systems, 18(1), 5-21. https://doi.org/10.1080/07421222.2001.11045672

Hakro, A. (2015). Public investment management system in Kuwait. International Journal of Applied Nonlinear Science, 2(1/2), 23-37. https://doi.org/10.1504/IJANS.2015.076520

Hargreaves, T. (2011). Practicing behaviour change: Applying social practice theory to pro-environmental behaviour change. Journal of Consumer Culture, 11(1), 79-99. https://doi.org/10.1177/1469540510390500

Hazzi, O., \& Maldaon, I. (2015). A pilot study: vital methodological issues business, Theory and Practice, 16(1), 53-62. https://doi.org/10.3846/btp.2015.437

Heisig, P. (2009). Harmonisation of knowledge management-comparing $160 \mathrm{KM}$ frameworks around the globe. Journal of Knowledge Management, 13(4), 4-31. https://doi.org/10.1108/13673270910971798

Henseler, J., Ringle, C., \& Sinkovics, R. (2009). The use of partial least squares path modelling in international marketing. In New challenges to international marketing (pp. 277-319). Emerald Group Publishing Limited.

Higgins, C., Duxbury, L., \& Irving, R. (1992). Work-family conflict in the dual-career family. Organizational Behavior and Human Decision Processes, 51(1), 51-75. https://doi.org/10.1016/0749-5978(92)90004-Q

Huang, J., \& Li, Y. (2009). The mediating effect of knowledge management on social interaction and innovation performance. International Journal of Manpower, 30(3), 285-301. https://doi.org/10.1108/01437720910956772

Huhtala, M., Tolvanen, A., Mauno, S. \& Feldt, T. (2015). The associations between ethical organizational culture, burnout, and engagement: A multilevel study. Journal of Business and Psychology, 30(2), 399-414. https://doi.org/10.1007/s10869-014-9369-2

Hulland, J. (1999). Use of partial least squares (PLS) in strategic management research: A review of four recent $\begin{array}{lllll}\text { studies. } & \text { Strategic } & \text { Management } & \text { Journal, } & \text { 195-204. }\end{array}$ https://doi.org/10.1002/(SICI)1097-0266(199902)20:2<195::AID-SMJ13>3.0.CO;2-7

Huy, Q. (2001). In praise of middle managers. Harvard Business Review, 79(8), 72-79.

Inkinen, H. (2016). Review of empirical research on knowledge management practices and firm performance. Journal of Knowledge Management, 20(2), 230-257. https://doi.org/10.1108/JKM-09-2015-0336

Janz, B., \& Prasarnphanich, P. (2003). Understanding the antecedents of effective knowledge management: The importance of a knowledge-centered culture. Decision Sciences, 34(2), 351-384. https://doi.org/10.1111/1540-5915.02328

Janz, B., Wehterbe, J., Colquitt, J., \& Noe, R. (1997). Knowledge worker team effectiveness: The role of 
autonomy interdependence, team development, and contextual support variables. Personnel Psychology, 50(4), 877-904. https://doi.org/10.1111/j.1744-6570.1997.tb01486.x

Jarzabkowski, P. (2005). Strategy-as-practice: An activity-based approach. London. Sage.

Jarzabkowski, P., Kaplan, S., Seidl, D., \& Whittington, R. (2016). On the risk of studying practices in isolation: linking what, who, and how in strategy research. Strategic Organization, 14(3), 248-259. https://doi.org/10.1177/1476127015604125

Jimenez-Jimenez, D., \& Sanz-Valle, R. (2008). Could HRM support organizational innovation? The International Journal of Human Resource Management, 19(7), 1208-1221. https://doi.org/10.1080/09585190802109952

Kalling, T. (2003). Knowledge Management and the Occasional Links with Performance. Journal of Knowledge Management, 7(3), 67-81. https://doi.org/10.1108/13673270310485631

Kataria, A., Garg, P., \& Rastogi, R. (2012). Employee Engagement and Organizational Effectiveness: The Role of Organizational Citizenship Behavior. International Journal of Business Insights and Transformation, 6(1), 102-113.

Khandwalla, P. (1977). The design of organizations. New York: Harcourt Brace Jovanovich.

Khoreva, V., Vaiman, V., \& Van Zalk, M. (2017). Talent management practice effectiveness: investigating employee perspective. Employee Relations, 39(1), 19-33. https://doi. org/10.1108/ER-01-2016-0005.

Kianto, A., Sáenz, J., \& Aramburu, N. (2017). Knowledge-based human resource management practices, intellectual capital and innovation. Journal of Business Research 81, 11-20. http://dx.doi.org/10.1016/j.jbusres.2017.07.018

Kiessling, T., Richey, R., Meng, J., \& Dabic, M. (2009). Exploring knowledge management to organizational performance outcomes in a transitional economy. Journal of World Business, 44(4), 421-433. https://doi.org/10.1016/j.jwb.2008.11

Kilmann, R. (1985). Corporate culture: managing the intangible style of corporate life may be the key to avoiding stagnation. Psychology Today, 19(4), 62-68.

Kirkman, B., \& Shapiro, D. (2001). The impact of cultural values on job satisfaction and organizational commitment in self-managing work teams: The mediating role of employee resistance. Academy of Management Journal, 44(3), 557-569. https://doi. org/10.5465/3069370

Kovač, P., Tomaževič, N., Leben, A., \& Aristovnik, A. (2016). Reforming public administration in Slovenia: between theory and practice of good governance and good administration. International Journal of Public Policy, 12(6), 130-148. https://doi.org/10.1504/IJPP.2016.079732

Lee, H., \& Choi, B. (2003). Knowledge management enablers, processes, and organizational performance: An integrative view and empirical examination. Journal of Management Information Systems, 20(1), 179-228. https://doi.org/10.1080/07421222.2003.11045756

Lok, P., \& Crawford, J. (2004). The effect of organisational culture and leadership style on job satisfaction and organisational commitment: A cross-national comparison. Journal of Management Development, 23(4), 321-338. https://doi.org/10.1108/02621710410529785

Lyles, M., \& Schwenk, C. (1992). Top management, strategy and organizational knowledge structures. Journal of Management Studies, 29(2), 155-174. https://doi.org/10.1111/j.1467-6486.1992.tb00658.x

Mathur, A. (2015). Relationship between Organisational Culture and HRM Practices: An Empirical Evidence from Indian Tourism Industry. International Journal of Research in Organizational Behavior and Human Resource Management, 3(4), 64-79.

Miller, D., \& Friesen, P. (1983). Strategy-making and environment: the third link. Strategic Management Journal, 4(3), 221-235. https://doi.org/10.1002/smj.4250040304

Nelson, R., \& Winter, S. (1982). An evolutionary theory of economic change. Cambridge, MA. Harvard University Press.

Nonaka, I., Toyama, R., \& Konno, N. (2000). SECI, Ba and leadership: A unified model of dynamic knowledge creation. Long Range Planning, 33(1), 5-34. https://doi.org/10.1016/S0024-6301(99)00115-6

O'Reilly, C. (1989). Corporations, culture, and commitment: Motivation and social control in organizations. California Management Review, 31(4), 9-25. https://doi.org/10.2307/41166580 
Palacios Marqués, D., \& José Garrigós Simón, F. (2006). The effect of knowledge management practices on firm $\begin{array}{lllll}\text { performance. Journal of Knowledge } & \text { Management, 10(3), 143-156. }\end{array}$ https://doi.org/10.1108/13673270610670911

Pedler, M., Burgoyne, J., \& Boydell, T. (1991). The learning company: A strategy for sustainable development. Maidenhead. McGraw-Hill.

Penrose, E., \& Penrose, E. (2009). The theory of the growth of the firm. Oxford. University Press.

Politis, J. (2003). The connection between trust and knowledge management: what are its implications for team performance. Journal of Knowledge Management, 7(5), 55-66. https://doi.org/10.1108/13673270310505386

Powell, T., Lovallo, D., \& Fox, C. (2011). Behavioral strategy. Strategic Management Journal, 32(13), 1369-1386. https://doi.org/10.1002/smj.968

Reinartz, W. Krafft, M., \& Hoyer, W. (2004). The customer relationship management process: Its measurement and impact on performance. Journal of Marketing Research, 41(3), 293-305. https://doi.org/10.1509/jmkr.41.3.293.35991

Robbins, S., \& Decenzo, D. (2001). Fundamentals of management: Essential concepts and applications. NJ. Prentice-Hall.

Rodriguez, J., \& Stewart, P. (2017). HRM and work practices in Chile: the regulatory power of organisational culture. Employee Relations, 39(3), 378-390. https://doi.org/10.1108/ER-02-2017-0034

Rurkkhum, S., \& Bartlett, K. (2012). The relationship between employee engagement and organizational citizenship behaviour in Thailand. Human Resource Development International, 1(2), 157-174. https://doi.org/10.1080/13678868.2012.664693

Saunders, M., Lewis, P., \& Thornhill, A. (2016). Research Methods for Business Students (7th ed.). England. Pearson.

Sciulli, L. (1998). How organizational structure influences success in various types of innovation. Journal of Retail Banking Service, 20(1), 13-18.

Sijtsma, K. (2009). On the use, the misuse, and the very limited usefulness of Cronbach's alpha. Psychometrika, 74, 107-120. http://doi.org/10.1007/s11336-008-9101-0

Simonin, B. (1997). The importance of collaborative know-how: An empirical test of the learning organization. Academy of Management Journal, 40(5), 1150-1174. https://doi.org/10.5465/256930

Sivadas, E., \& Dwyer, F. (2000). An examination of organizational factors influencing new product success in internal and alliance-based processes. Journal of Marketing, 64(1), 31-50. https://doi.org/10.1509/jmkg.64.1.31.17985

Skyrme, D., \& Amidon, D. (1997), Creating the knowledge-based business. London: Business Intelligence Limited.

Spreitzer, G. (1995). Psychological empowerment in the workplace: Dimensions, measurement, and validation. Academy of Management Journal, 38(5), 1442-1465. https://doi.org/10.5465/256865

Tiwana, A. (2004). An empirical study of the effect of knowledge integration on software development performance. Information and Software Technology, 46(13), 899-906. https://doi.org/10.1016/j.infsof.2004.03.006

Torabi, M., Kyani, A., \& Falakinia, H. (2016). An investigation of the impact of knowledge management on human resource performance in management of Keshavarzi bank branches in Tehran. Procedia-Social and Behavioral Sciences, 230, 471-481. https://doi.org/10.1016/j.sbspro.2016.09.059

Ukil, M., \& Akkas, M. (2017). Determining success factors for effective strategic change: role of middle managers' strategic involvement. Serbian Journal of Management, 12(1), 29-40. https://doi.org/10.5937/sjm12-11430

Venkatraman, N. (1989). Strategic orientation of business enterprises: The construct, dimensionality, and measurement. Management Science, 35(8), 942-962. https://dl.acm.org/doi/10.5555/70578.70581

Von Krogh, G. (1998). Care in knowledge creation. California management review, 40(3), 133-153. https://doi.org/10.2307/41165947

Von Krogh, G., Nonaka, I., \& Rechsteiner, L. (2012). Leadership in organizational knowledge creation: A review 
and framework. Journal of Management $\quad$ Studies, $49(1), \quad 240-277$. https://doi.org/10.1111/j.1467-6486.2010.00978.x

Watkins, K., \& Marsick, V. (1996). In action, Creating the Learning Organization. Alexandria VA. American Society for Training and Development.

Westfall, P., \& Henning, K. (2013). Texts in statistical science: Understanding advanced statistical methods. Boca Raton, FL. Taylor \& Francis.

Wold, H. (1975). Soft modelling by latent variables: the non-linear iterative partial least squares (NIPALS) approach. Journal of Applied Probability, 12(S1), 117-142. https://doi.org/10.1017/S0021900200047604

Wold, H. (1982). Systems Under Indirect Observation Using PLS. In C. Fornell (Ed.), A Second Generation of Multi variate Analysis (pp. 325-347). New York: Praeger.

Wold, H. O. A. (1982). Soft Modeling: The Basic Design and Some Extensions. In K.G. Joreskog and H. O. A. Wold (Eds.), Systems under Indirect Observations (pp. 1-54). North-Holland, Amsterdam.

Wold, S., Ruhe, A., Wold, H., \& Dunn, I. (1984). The collinearity problem in linear regression. The partial least squares (PLS) approach to generalized inverses. SIAM Journal on Scientific and Statistical Computing, 5(3), 735-743. https://doi.org/10.1137/0905052

Yang, J. (2010). The knowledge management strategy and its effect on firm performance: A contingency analysis. International Journal of Production Economics, 125(2), 215-223. https://doi.org/10.1016/j.ijpe.2010.03.012

Yap, A., \& Bjoern-Andersen, N. (1998). Energizing the nexus of corporate knowledge: a portal toward the virtual organization. ICIS 1998 Proceedings, 24.

Young, G., Sapienza, H., \& Baumer, D. (2003). The influence of flexibility in buyer-seller relationships on the productivity of knowledge. Journal of Business Research 56(6), 443-451. https://doi.org/10.1016/S0148-2963(01)00243-0

Zaitouni, M., Harraf, A., \& Kisswani, A. (2020). Resources for development: the relationship of HRM practices and continuous learning culture with training success. International Journal of Human Resources Development and Management, 20(1), 75-92. https://doi.org/10.1504/IJHRDM.2020.105099

Zheng, W., Yang, B., \& McLean, G. (2010). Linking organizational culture, structure, strategy, and organizational effectiveness: Mediating role of knowledge management. Journal of Business Research, 63(7), 763-771. https://doi.org/10.1016/j.jbusres.2009.06.005

\section{Copyrights}

Copyright for this article is retained by the author(s), with first publication rights granted to the journal.

This is an open-access article distributed under the terms and conditions of the Creative Commons Attribution license (http://creativecommons.org/licenses/by/4.0/). 